\title{
Changes in children's lung function over two decades in relation to socioeconomic, parental and household factors in Wuhan, China
}

\author{
Suzhen $\mathrm{Cao}^{1}$, Dongsen Wen ${ }^{1}$, Sai Li ${ }^{1}$, Qian Guo ${ }^{1}$, Xiaoli Duan ${ }^{1}$, Jicheng Gong ${ }^{2}$, Xiangyu Xu', Xin Meng ${ }^{2}$, \\ Ning Qin ${ }^{1}$, Beibei Wang ${ }^{1}$, Junfeng Jim Zhang ${ }^{3,4,5}$
}

${ }^{1}$ Beijing Key Laboratory of Resource-oriented Treatment of Industrial Pollutants, School of Energy and Environmental Engineering, University of Science and Technology Beijing, Beijing, China; ${ }^{2}$ Beijing Innovation Center for Engineering Science and Advanced Technology, State Key Joint Laboratory for Environmental Simulation and Pollution Control, College of Environmental Sciences and Engineering, And Center for Environment and Health, Peking University, Beijing, China; ${ }^{3}$ Nicholas School of the Environment and Duke Global Health Institute, Duke University, Durham, USA; ${ }^{4}$ Global Health Research Center, Duke Kunshan University, Kunshan, China; ${ }^{5}$ Guangzhou Institute of Respiratory Health, The First Affiliated Hospital of Guangzhou Medical University, Guangzhou, China

Contributions: (I) Conception and design: (I) Conception and design: JJ Zhang, J Gong, X Duan; (II) Administrative support: X Duan, S Cao; (III) Provision of study materials or patients: S Cao, X Duan; (IV) Collection and assembly of data: S Cao, S Li, Q Guo, X Xu; (V) Data analysis and interpretation: D Wen, S Li, Q Guo, J Gong, N Qin, B Wang, X Meng; (VI) Manuscript writing: All authors; (VII) Final approval of manuscript: All authors.

Correspondence to: Xiaoli Duan, PhD. University of Science and Technology Beijing, 30 Xueyuan Road, Beijing 100083, China. Email: jasmine@ustb.edu.cn.

Background: It is important to identify risk and beneficial factors for children's lung function. This study aims to ascertain potential changes in children's lung function in relation to changes in socioeconomic, parental and household factors, based on a comparison between two periods spanning 25 years in Wuhan, the largest metropolis in central China.

Methods: In two cross-sectional studies, lung function measurements and questionnaire surveys were conducted on school-age children in 1993-1996 (Period I) and in 2018 (Period II). Children of 6-12 years old from elementary schools were selected by a multistage sampling method. Demographic information, socioeconomic status, feeding methods, parental illness and behavior patterns, as well as household characteristics, were collected through a questionnaire survey. Spirometric lung function was measured, including forced vital capacity (FVC), forced expiratory volume in the first second $\left(\mathrm{FEV}_{1}\right)$, forced expiratory flow at $25 \%$ and $75 \%$ of the pulmonary volume (FEF25-75), and peak expiratory flow (PEF). Wilcoxon analysis of variances was used to assess the differences in lung function indexes between Period I and Period II. Multiple linear regression models were used to estimate the association of lung function with regard to socioeconomic, parental and household factors, respectively.

Results: Significant prevalence reductions were observed for household coal use, paternal smoking and maternal asthma, while the prevalence increased significantly for children sleeping in their own rooms or own beds and breastfeeding, ventilation use during cooking, and parental education level from Period I to Period II. When adjusted for age, height, weight, sex and other factors assessed in the study, children had significant lower values of FVC, $\mathrm{FEV}_{1}$, and PEF in Period II than in Period I. Enclosed kitchen was significantly associated with lower lung function in children in Period I. Urban living condition and higher maternal education level were each associated with a higher FVC, while father having no fixed income was associated with a lower FVC and a lower $\mathrm{FEV}_{1}$, respectively, in Period II. In comparison with Period I, the beneficial impact of urban living and that of breastfeeding were enhanced and the detrimental effect of poor household condition was weakened in Period II.

Conclusions: Lung function was lower in 2018 than in 1993-1996 in school-age children living in Wuhan. Although improvements in urban living and household environmental conditions as well as increased breastfeeding in Period II could have contributed to increased lung function, other unmeasured risk factors 
may have played a more dominant role in leading to a net decrease in lung function from Period I to Period II. Future studies are needed to identify these risk factors.

Keywords: Lung function; school children; household characteristics; parental factor; socioeconomic levels

Submitted Jan 25, 2021. Accepted for publication Jun 03, 2021.

doi: $10.21037 /$ jtd-21-158

View this article at: https://dx.doi.org/10.21037/jtd-21-158

\section{Introduction}

Lung function testing using the spirometry plays a key role in the prevention and diagnosis of respiratory disease $(1,2)$. Forced expiratory volume in the first second $\left(\mathrm{FEV}_{1}\right)$ and forced vital capacity (FVC), reflecting the mechanical properties of large airway and the maximum volume of air exhaled from the lungs in a forced breath (3), are most commonly used lung function indexes $(4,5)$. As a complex trait, lung function can vary and be changed by both genetic and environmental factors (6-9). In addition to genetic factors $(6,7)$ and outdoor air pollution $(8,9)$, many studied have demonstrated that the factors such as socioeconomic status $(10,11)$, passive smoking (environmental tobacco smoking) $(12,13)$, household indoor environmental determinants (including solid fuel use, ventilation condition and mold, etc.) $(14,15)$, and breastfeeding (16) can impact the development of lung function.

An epidemiologic study based on three cohorts over 13 years, i.e., from 1994 to 1998, 1997 to 2001 and 2007 to 2011, found that the improvements in 4-year growth of both $\mathrm{FEV}_{1}$ and $\mathrm{FVC}$ for the children aged from 11 to 15 years old were significantly associated with declining levels of some air pollutants (17). A large population-based cross-sectional study of school-aged children in seven northeastern cities of China found that children who were breastfed had greater spirometric lung function values and a lower prevalence of impaired lung function compared with children who were not breastfed (16). In the last three decades, substantially changes in socioeconomic level, environmental conditions and lifestyles have occurred with the rapid economic development and urbanization in Chinese cities. Consequently, whether children's lung function in China is getting better or worse is debatable, owing in large part to a lack of follow-up studies. It is important to answer this question so that beneficial factors and risk factors can be identified to improve children's respiratory health.

In 1993-1996, a cross-sectional study was conducted to investigate the respiratory health including lung function and to identify the influencing factors among elementary school children in Wuhan, China $(18,19)$. The data from this early study provide unique baseline information to support a follow-up study in the same city to evaluate potential changes in children's lung function, which may be associated with the changes in the influencing factors identified in the earlier period. Hence, we conducted another cross-sectional study using a similar survey and spirometry protocols in 2018. We term the 1993-1996 study as Period I study and the more recent study as Period II study. The objective of the current analysis is to examine whether children with the same age and living in the same city had same lung function values in the two periods and whether changes in socioeconomic, parental and household factors have contributed to potential changes in lung function. We present the following article in accordance with the STROBE reporting checklist (available at https:// dx.doi.org/10.21037/jtd-21-158).

\section{Methods}

\section{Study site and participants}

As the capital of Hubei province, Wuhan is the largest metropolis and the only sub-provincial city in central China. It has subtropical monsoon climate, with annual average temperature of $17.3{ }^{\circ} \mathrm{C}$ in 2018 (20). There were about $80 \%$ urban residents, and a total of 11.08 million residents living on the $8,569.15 \mathrm{~km}^{2}$ land area in 2018 in Wuhan (20). With the requirement of the National Development and Reform Commission, Wuhan has experienced rapid economic development, accompanied with changes in population, socioeconomic and living environment over the past two decades (20). The investigation of Period I (before the rapid changes started) was conducted in an elementary school from an urban area (Wuchang district) and another elementary school from a suburb (Huangpi district) in Wuhan. In Period II, the study was carried out 
in two elementary schools from two urban areas (Wuchang and Qingshan districts) and in one elementary school from a suburban area (Huangpi district).

The Period I study was carried out during the period of 1993-1996 and the lung function tests were repeated in summer and winter in each year, as described previously $(18,19)$. Briefly, 491 children $(56.6 \%$ in urban) with an age range of 6 to 12 years old, who participated both the questionnaire survey and lung function tests were included in the current analysis. In Period II, since the two original schools of Period I were either closed or combined with other institutions, three other elementary schools as close to the sites of the original schools as possible were selected. Within each school, we randomly selected 1 to 3 classes from each grade, depending on the class size, to enroll study participants. After obtaining permission from each school principal, we provided class adviser with information packets containing a description of the study and a blank informed consent to the students as well as their parents or guardians. These explained the objective of the study and the main content of the questionnaire, and informed the voluntary and noncompulsory nature of their participation. After having received signed consent forms, we handed out the questionnaires to the students and asked their parents or guardians to complete the questionnaire. In selecting a sub-sample of students for lung function tests, we excluded those who had lived in their residential district less than 3 years. The study protocol was reviewed and approved by the Ethics Committee of Biomedical Research, Duke Kunshan University, Jiangsu (No. FWA00021580), with the need for individual patient consent waived.

\section{Questionnaire survey and data collection}

The questions regarding the factors potentially influencing lung function were kept the same as much as applicable in the two periods $(15,21)$. These included the questions about children's sociodemographic factors, feeding patterns during infancy, living conditions such as whether sleeping in own rooms or own beds, parental respiratory disease histories and smoking status, socioeconomic level, and household environmental conditions (e.g., kitchen style, types of fuels used for cooking or/and heating, and ventilation conditions). In Period II, new questions were added as we considered these emerging as relevant factors. For example, we asked about the presence of pets, recent interior renovation, presence of mold, use of air fresheners, use of mosquito repellents, use of air purifiers, and whether children were born preterm. The questionnaires were filled out by the parents or guardians of children, with assistance (e.g., clarifying questions) from our trained research staff when needed. All questionnaire responses were electronically recorded in a database according to a standardized code book and file structure.

The socioeconomic class of the participants was determined based on ranked assessment of the parental occupation and highest educational qualification as described previously (22). Kitchen style refers to enclosed kitchen or separated kitchen (visualized as shown in Figure S1), coal fuel use was defined from the question of "What was the main fuel type for cooking?" and "What was the main fuel type for heating?" Ventilation use was defined by the "Yes" answer to the question of "Was there a ventilation device in the kitchen when cooking?" We combined information on coal use either for cooking or for heating to create a binary variable as household coal use (yes vs. no). The presence of all ventilation devices (chimney, hood, and exhaust fan) was collapsed to create a binary variable: ventilation use (yes $v s$. no). Parental information on education was set as a binary variable: below college vs. with or above college. Parental information on occupation was classified by the white collar (e.g., teachers, governmental office workers), blue collar (e.g., farmers, and factory workers), and other occupation without a fixed income.

\section{Anthropometric measurement}

Since children's lung function is strongly determined by height and weight (23), we conducted the anthropometric measurement before the lung function test. The body weight and height of the children in their bare feet were measured to $0.1 \mathrm{~kg}$ and $0.5 \mathrm{~cm}$, respectively, using a routinely calibrated anthropometer (Jiangsu Suhong Medical Equipment Co. Ltd., China). Children were required to put their feet together with their heels, buttocks, and occiput touching the wall while they looked straight ahead to ensure accurate measurement of their height. Body mass index (BMI) $\left(\mathrm{kg} / \mathrm{m}^{2}\right)$ was calculated using the weight $(\mathrm{kg})$ divided by height $(\mathrm{m})$ squared.

\section{Lung function measurement (spirometry)}

The standardized spirometry protocol of the American Thoracic Society (ATS) was applied to measure lung function using computerized Warren E. Collins Survey II 8-liter water-seal volume spirometers in Period I and 
portable spirometer III (Spiro-lab MIR, Co. Ltd., Italy) in Period II by trained technicians (24). Children received spirometry measurement in the standing position in a dedicated room in school hours. Measured lung function indexes included FVC, $\mathrm{FEV}_{1}$, peak expiratory flow (PEF), and the mid-expiratory flow (FEF25-75), in both study periods. For each participant, the spirometry test was repeated up to five times until acceptable, reproducible flow-volume loops were generated (24). Between one test and the next, the device evaluates the repeatability of the following parameters: repeatable when the difference between the two highest FVC values was $\leq 150 \mathrm{~mL}$ and the $\mathrm{FEV}_{1}$ value was $\leq 150 \mathrm{~mL}$ (24). Acceptable spirograms were defined as a smooth flow-volume curve without artifacts and satisfactory exhalation of forced expiratory duration $>6 \mathrm{~s}$ ( $3 \mathrm{~s}$ for children younger than 10 years). If the difference between the two largest FVC values were within $150 \mathrm{~mL}$, the test was concluded. The two largest acceptable and concluded values of the parameters were selected and averaged for statistical analysis.

\section{Statistical analysis}

Data were tested for normality (Shapiro-Wilks $W$-test) and homogeneity (Bartlett's test for unequal variances). Categorical variables (e.g., sex) were presented as the number (percentage) in each subgroup, and continuous variables (e.g., age) were present as mean \pm standard deviation (SD). Differences in lung function (continuous variable) between categorical variables (e.g., sex) or between the two study periods were analyzed using Wilcox test, whereas categorical variables between two study periods were analyzed using Pearson's Chi-square $\left(\chi^{2}\right)$ tests, as appropriate. Univariate logistic regression analyses were conducted to examine the association between variables and lung function parameters both for Period I and Period II. Multi-variate linear regressions were used to examine the association between variables and lung function indexes. To identify the change in the contribution of influencing factors on lung function, the interaction between period and a certain variable was added in the regression model. Accordingly, the interaction between period and district, parental occupation and education level, or a household factor was assessed. Adjusted coefficient ( $\beta$ ) with $95 \%$ confidence intervals (95\% CIs) for each of the independent variables was calculated. These variables (surveyed in both periods) included age, sex, height, weight, district, paternal smoking, maternal smoking, sleep in own room, sleep in own bed, household coal use, ventilation use when cooking, paternal occupation, maternal occupation, paternal education level, and maternal education level, and the interaction terms when assessing the interactions. All statistical tests were two tailed, and statistical significance was declared when a $\mathrm{P}$ value was $<0.05$. All analyses were performed using SPSS software for Windows, version 22 (SPSS Inc., Chicago, IL, USA).

\section{Results}

\section{Characteristics of participants}

In Period I, the lung function was measured multiple times in summer (May-June) and winter months, respectively. The lung function tests were only performed in June, 2018 in Period II. For comparability, we used lung function data collected in one summer (1993) in Period I in the current analysis. This resulted in a sample size of 491 in Period I and a sample size of 383 in Period II. The characteristics of the participants stratified by sociodemographic, household and parental factors, as well as the statistical difference of the characteristics, are shown in Table 1.

The mean (SD) age of the participants in Period I and Period II were 8.4 (1.2) and 9.4 (1.2) years, respectively. More boys were recruited in Period II (57.2\%) than in Period I $(49.9 \%)(\mathrm{P}<0.05)$. A higher fraction of children lived in an urban district in Period II (63.7\%) than in Period I $(56.6 \%)(\mathrm{P}<0.001)$. A higher proportion of children was breastfed during infancy in Period II $(76.2 \%)$ than in in Period I $(72.1 \%)(\mathrm{P}=0.003)$.

\section{Sociodemographic, housebold and parental factors}

The prevalence of paternal smoking showed a substantial decrease from Period I (85.7\%) to Period II (45.2\%). Maternal smoking rate was low $(\leq 0.6 \%)$ in both periods. Asthma prevalence was significantly lower in mothers and non-significantly lower in fathers in Period II. In contrast, bronchitis prevalence was significantly higher in fathers and nearly the same in mothers in Period II (Table 1).

Fewer families used coal as a household fuel in Period II $(2.9 \%)$ than in Period I (46.8\%). Using a ventilation device during cooking was much more common in Period II $(90.1 \%)$ than in Period I $(39.5 \%)$. More families had enclosed kitchen in Period II $(65.0 \%)$ than in Period I (50.3\%). More children had own bedrooms and own beds in Period II. The proportions of higher educational attainment (with or above college) in both fathers and mothers were 
Table 1 Sociodemographic, parental, household and socioeconomic information of the school children in Period I (1993-1996) and Period II (2018)

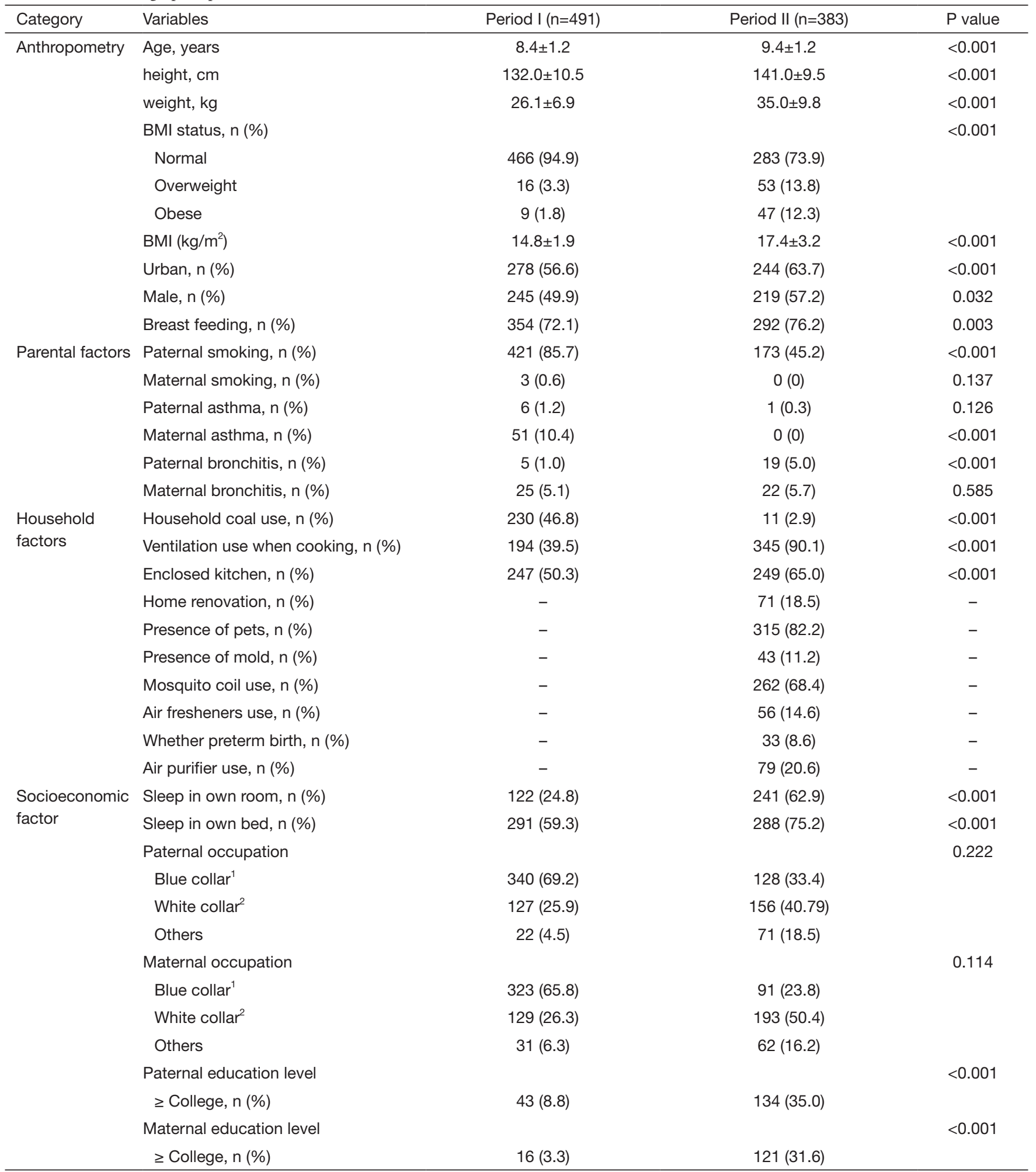

Values are mean (SD) or number (percentage). ${ }^{1}$ " "White collar" includes teacher, businessperson, clerk, housewife (few cases), and other non-manual laborer occupations; ${ }^{2}$, "Blue collar" refers to factory worker, construction worker, building cleaning worker, farmer, and other manual laborer occupations. BMI, body mass index; SD, standard deviation. 
Table 2 Children's lung function (unadjusted) in Period I and Period II, and the estimated changes (95\% confidence interval) from Period I to Period II in adjusted* lung function

\begin{tabular}{lccccc}
\hline \multirow{2}{*}{ Lung function Index } & \multicolumn{3}{c}{ Unadjusted mean (SD) } & & \multicolumn{2}{c}{ (Period II - Period I) difference* $^{*}$} & Period I & Period II & P value & Estimate $(95 \%$ Cl) & P value \\
\cline { 2 - 3 } & $1,930(464)$ & $1,830(531)$ & $<0.001^{\#}$ & $-468(-536,-401)$ & $<0.001^{\#}$ \\
FVC, mL & $1,590(362)$ & $1,740(439)$ & $<0.001^{\#}$ & $-175(-230,-119)$ & $<0.001^{\#}$ \\
FEV $1, \mathrm{~mL}$ & $4,940(1,870)$ & $3,400(1,020)$ & $<0.001^{\#}$ & $-1,845(-2,172,-1,517)$ & $<0.001^{\#}$ \\
PEF, mL/s & $1,790(456)$ & $2,410(669)$ & $<0.001^{\#}$ & $296(187,405)$ & $<0.001^{\#}$ \\
FEF25-75, mL/s & &
\end{tabular}

*, adjusted for age, sex, height, weight, district, father smoking, mother smoking, sleeping in own room, sleeping in own bed, household coal use, ventilation use when cooking, paternal occupation, maternal occupation, paternal education level, maternal education level, breast feeding, paternal asthma, maternal asthma, paternal bronchitis and maternal bronchitis. ", statistically significant. SD, standard deviation; FVC, forced vital capacity; FEV $_{1}$, forced expiratory volume in the first second; PEF, peak expiratory flow; FEF25-75, forced expiratory flow at $25 \%$ and $75 \%$ of the pulmonary volume.

significantly increased from Period I to Period II. All these differences were statistically significant $(\mathrm{P}<0.001)$. However, the rate of children's parents being a white-collar worker was similar in both periods.

\section{Anthropometry and lung function}

Height, weight and BMI were all significantly higher in Period II, largely consistent with the fact that children were significantly older (by 1 year) in Period II than in Period I (Table 1). Even with anticipated increases in children's lung function with increasing age (height, weight), unadjusted raw values of FVC and PEF were still lower in Period II than in Period I (Table 2). After adjusting for age, sex, height, and weight, as well as potential influencing household and parental factors, FVC, FEV, PEF all had a significantly lower value in Period II $(\mathrm{P}<0.001)$, reflecting a $24 \%, 11 \%$, and $37 \%$ decline in $\mathrm{FVC}, \mathrm{FEV}_{1}$, and $\mathrm{PEF}$, respectively, from Period I. In contrast, adjusted FEF25-75 was significantly higher (with a $17 \%$ increase) in Period II.

\section{Association of lung function with sociodemographic, household and parental factors}

As expected, increasing height was, consistently across both Period I and II, associated with higher values of FVC, $\mathrm{FEV}_{1}$, PEF, FEF25-75, respectively, confirming that height is an important predictor for these lung function indexes in elementary school children. Increasing weight was consistently associated with increasing $\mathrm{FVC}$ and $\mathrm{FEV}_{1}$, respectively. As a continuous variable, BMI was positively associated with all the four indexes. Girls appeared to have lower FVC, $\mathrm{FEV}_{1}$, and PEF values with or without a statistical significance (see Table 3).

The associations of children's lung function indexes with socioeconomic, household and parental factors are also shown in Table 3 by period. In Period II, children living in an urban district had significantly higher FVC and PEF values in comparison with those living in a suburb. Having an outside or separated kitchen was associated with higher FVC $(\mathrm{P}<0.01)$ and $\mathrm{FEV}_{1}(\mathrm{P}<0.05)$ in Period I. Fathers having no stable income were significantly associated with lower FVC and $\mathrm{FEV}_{1}$ in Period II. A higher maternal education level was significantly associated with higher FVC and $\mathrm{FEV}_{1}$ values in Period II. No significant associations were observed between children's lung function and the new factors assessed in Period II (e.g., presence of pets, presence of mold, and others listed in the bottom of Table 3).

Furthermore, to assess the changes of the potential influencing factors on children's lung function, the factors including living area (urban or suburban), household conditions (i.e., household coal use, ventilation use when cooking, enclosed kitchen), breastfeeding, and parental occupation and education status, were selected for interaction analysis based on Table 3 and previous research (25). We found that the beneficial effect of urban living environment on PEF showed a growth change (Table S1). Furthermore, breastfeeding showed an increasing positive effect on PEF in children after controlling for confounding factors such as height, weight, and parental and household factors.

\section{Discussion}

Lung function measurement is an important clinical 
Table 3 Effects of anthropometric, socioeconomic, parental and household factors on children's lung function in Period I and Period II, respectively. The effect estimates for continuous variables are changes in lung function indexes per unit change in the variable and those for categorical variables are differences from the reference group

\begin{tabular}{|c|c|c|c|c|c|c|c|c|}
\hline Variables & \multicolumn{2}{|c|}{$\mathrm{FVC}(\mathrm{mL})$} & \multicolumn{2}{|c|}{ FEV1 (mL) } & \multicolumn{2}{|c|}{$\mathrm{PEF}(\mathrm{mL} / \mathrm{s})$} & \multicolumn{2}{|c|}{ FEF25-75 (mL/s) } \\
\hline Age (year) & 6.3 & 21.6 & $38.5^{\star \star}$ & 10.5 & $-323.3^{\star \star}$ & 24.2 & $150.8^{\star *}$ & 3.6 \\
\hline Height (cm) & $28.6^{\star \star}$ & $10.5^{*}$ & $22.3^{\star \star}$ & $13.9^{\star \star}$ & $97.7^{\star \star}$ & $26.5^{\star}$ & $14.1^{\star \star}$ & $22.1^{\star \star}$ \\
\hline Weight (kg) & $16.7^{\star \star}$ & $13.3^{\star \star}$ & $7.8^{\star \star}$ & $10.3^{\star \star}$ & -4.5 & $24.2^{\star}$ & -1.4 & 12.0 \\
\hline Sex (ref: male) & $-99.7^{\star \star}$ & -16.6 & $-90.6^{\star \star}$ & -5.8 & -154.4 & -111.1 & $-91.1^{\star \star}$ & 70.6 \\
\hline District (ref: urban) & 14.9 & $-156.6^{\star \star}$ & 3.3 & -85.2 & $-1,155.9^{\star \star}$ & 11.0 & 47.3 & 81.7 \\
\hline Breast feeding (ref: no) & -16.7 & 44.5 & -14.8 & 55.7 & -189.3 & 121.0 & -50.1 & 101.7 \\
\hline Father smoking (ref: no) & 44.5 & 3.1 & 32.1 & 12.0 & 38.9 & -31.8 & 86.9 & -38.3 \\
\hline Sleep in own bed (ref: yes) & 32.6 & 58.7 & 15.1 & 57.1 & 15.4 & -20.0 & 14.0 & 37.6 \\
\hline Household coal use (ref: no) & 13.7 & -41.6 & -13.3 & -7.9 & 236.2 & 342.4 & -35.6 & 392.3 \\
\hline Ventilation use when cooking (ref: no) & -10.8 & 279.8 & 22.6 & 169.4 & 87.0 & 297.6 & 57.1 & -12.3 \\
\hline Enclosed kitchen (ref: no) & $-55.3^{\star \star}$ & -36.5 & $-36.9^{*}$ & -20.0 & 72.0 & 19.3 & -18.2 & 12.5 \\
\hline Father being white collar (ref: blue collar) & 32.5 & -66.8 & 30.1 & -49.1 & -224.9 & 199.8 & 49.3 & 232.1 \\
\hline Father without stable income (ref: blue collar) & 55.1 & $-192.1^{*}$ & 1.8 & $-171.8^{*}$ & -200.7 & -236.9 & 80.4 & -88.4 \\
\hline Mother being white collar (ref: blue collar) & -36.0 & 113.2 & -6.2 & 90.2 & -9.7 & 27.0 & 36.6 & 6.4 \\
\hline Mother without stable income (ref: blue collar) & 61.8 & -8.9 & 60.5 & -26.0 & 273.1 & -21.6 & 33.8 & 82.0 \\
\hline Maternal bronchitis (ref: no) & 15.7 & -66.2 & 44.5 & -41.8 & -112.8 & 364.6 & 77.6 & 285.6 \\
\hline Home renovation (ref: no) & NA & -66.0 & NA & -61.3 & NA & -128.3 & NA & -55.1 \\
\hline Presence of pets (ref: no) & NA & 34.1 & NA & 9.5 & NA & -153.3 & NA & -43.6 \\
\hline Presence of mold (ref: no) & NA & 77.0 & NA & 89.5 & NA & 131.3 & NA & 191.9 \\
\hline Mosquito coil use (ref: no) & NA & 2.0 & NA & -7.9 & NA & -58.0 & NA & 68.2 \\
\hline Air freshener use (ref: no) & NA & 55.6 & NA & 67.7 & NA & -35.0 & NA & 28.1 \\
\hline Whether preterm birth (ref: no) & NA & -75.1 & NA & -110.9 & NA & -166.4 & NA & -142.7 \\
\hline Air purifier use (ref: no) & NA & -57.6 & NA & -45.1 & NA & -266.1 & NA & -179.0 \\
\hline
\end{tabular}

-, no data, since the prevalence rate in the period was too low. ${ }^{*}, \mathrm{P}<0.05 ;{ }^{* *}, \mathrm{P}<0.01$. NA, not available; FVC, forced vital capacity; $\mathrm{FEV}_{1}$, forced expiratory volume in the first second; PEF, peak expiratory flow; FEF25-75, forced expiratory flow at $25 \%$ and $75 \%$ of the pulmonary volume. 
practice to determine lung capacity and possible deterioration of the mechanical function of the lungs, respiratory muscles, and chest wall (23). Spirometry is the gold standard technique to measure lung function in children aged $\geq 6$ years and in adults (2). In clinical guidelines, the interpretation of lung function, mostly using spirometry tests, has historically been based on the most important anthropometric factors, such as weight, height, sex, and age (26). In this study, FVC, $\mathrm{FEV}_{1}$, PEF, and FEF25-75 in children were increased with the increase of age, height, weight and BMI. Pulmonary maturity is reached at about 20-25 years of age (27), after which lung function progressively begins to decline (28), particularly for the most affected parameters such as FVC and $\mathrm{FEV}_{1}$ (29), due to decreased compliance of the chest wall, loss of expiratory muscle strength and the growing tendency of the smaller airways to close during forced expiration (30). For the participants with an age of 6-12 years in this study, $\mathrm{FVC}$ and $\mathrm{FEV}_{1}$ increased with increasing age. Additionally, several parameters, such as $\mathrm{FVC}$ and $\mathrm{FEV}_{1}$ (which are proportional to body size) are affected by height (31), meaning that a taller child accordingly has a greater lung capacity. There are contradictions in the association of lung function with weight: some authors claim that obesity generally does not cause $\mathrm{FEV}_{1}$ and FVC to fall (32), and most spirometric values fall when weight is low (33). However, some studies suggest that obesity can cause airway limitation and bring about a parallel reduction in $\mathrm{FEV}_{1}$ and FVC (34). These discrepancies mainly are attributed to the exclusive use of the concept of BMI as a measure of obesity, while other relevant factors, such as waist circumference and waist-to-hip ratio, are ignored (35). A cross-sectional study conducted in United Kingdom found that $\mathrm{FEV}_{1}$ increased with increasing BMI to a threshold BMI of 23 , beyond which the increase in $\mathrm{FEV}_{1}$ was marginal (36). Given mean levels of BMI $\left(\mathrm{kg} / \mathrm{m}^{2}\right)$, i.e., 14.8 and 17.4 in Period I and Period II, respectively, the finding in our study is supported by a population-based cohort study reporting that a higher $\mathrm{BMI}$ is associated with improvements in lung function (37). Furthermore, since there are significant increased rates of overweight and obesity children in the later survey, in order to assess the effects of stratified BMI on the lung function in children, we compared the lung function level in children based on different BMI for Period II, i.e., normal, overweight and obesity, as shown in Table S2. And, the association of stratified BMI to children's lung function after controlling other confounders was analyzed as shown in Table S3. We found there were significant differences in the children's lung function among the children with different BMI conditions, and found that the overweight and obesity children had higher levels of lung function such as FVC and $\mathrm{FEV}_{1}$. With regard to sex, since biological males typically have larger lungs and more bronchioles than biological females who have the same weight and height (23), it is reasonable that the lung function parameters in males were higher than those in females in our study, particularly in Period I.

In Period II, a negative association was observed between living in a suburban area and lung function, particularly for FVC and PEF among elementary school children in Wuhan city, which contradicts with findings of earlier epidemiology studies $(38,39)$. Acrosssectional study, conducted among school-age children (5-15 years old) from the capital and the rural district in Mongolia, reported that $\mathrm{FEV}_{1}$ was $40 \%$ higher in rural Mongolian children than in urban children (40). A cohort study named the Saskatchewan Rural Health Study also reported that higher $\mathrm{FEV}_{1}$ and FVC were seen among children living on a farm due to a "farm effect" (41). However, the GABRIEL Advanced Studies demonstrated that there was no "farm effect" on lung function in children aged 6 to 12 years (42). Actually, the discrepancy observed in lung function in children between rural and urban areas can be interpreted and attributed to other important factors, such as ambient air pollution $(8,9,17)$, socioeconomic status $(10,11)$, and household indoor environment $(14,15)$. With rapid urbanization and industrialization, socioeconomic developments are inevitably associated with increase in environmental pollution levels. Regarding the study areas (i.e., Wuchang, Huangpi, and Qingshan), Huangpi was committed to the development of industrialization and urbanization with heavy construction activities such as subway and building construction, while Qingshan was a typical industrial district with several iron and steel enterprises, and Wuchang was historically regarded as the center of education and culture with a large amount of traffic emission. Thus, the highly urbanized environment in suburban areas which is associated with large emission of air pollution may lead to lower lung function in children, while the urban environments, which have already experienced urban infrastructure construction and have higher socioeconomic levels, could be associated with higher lung function level. Furthermore, the detrimental effect of suburban environmental exposure on children's lung function was strengthening over time, as shown in Table S1. $\mathrm{PM}_{2.5}$ and $\mathrm{SO}_{2}$ have been shown to have adverse effects on 
lung function in children regardless of living in urban or suburban areas $(16,17)$. The levels of these pollutants are expected to be higher in areas with industrial sources. A study conducted in Wuhan indicated that the areas with heavy air pollution have shifted from urban to rural areas in the last ten years due to frequent industrial activities and production activities (43). Additionally, after 25 years, there was no clear cut between urban and suburban areas in the determinant household conditions involved with fuel used in cooking/heating, ventilation use, etc. (see Table S4). Given that situation, we speculate that the higher levels of air pollutants such as $\mathrm{PM}_{2.5}$ and $\mathrm{SO}_{2}$ in suburban Wuhan may be one of the reasons for the detrimental effect of rural environmental exposure on children's lung function (see Figure S2).

Recent studies conducted in Chongqing (15) and in Pearl River Delta (21) in China found that indoor environmental exposure could lead to reduced lung function. We also found that having an enclosed kitchen (i.e., inside kitchen without isolation) was negatively associated with FVC and $\mathrm{FEV}_{1}$ in Period I. In our study, we defined an enclosed kitchen as a kitchen that was not isolated to the living room or bedroom with a door or other device, which can make air diffusion possible and expose the residents to cooking fume/smoke emitted from the kitchen. A study focused on the characteristics of indoor air pollution and estimation of respiratory dosage under varied fuel-type and kitchen-type in India indicated that kitchen configuration was an important factor for determining $\mathrm{PM}\left(\mathrm{PM}_{1}, \mathrm{PM}_{2.5}\right.$ and $\mathrm{PM}_{10}$ ) concentration, especially for biomass-based households. The same study found that PM concentrations were significantly higher in enclosed indoor kitchens as compared to separate outdoor kitchens, and enclosed indoor kitchen types exhibited a maximum intensification of 10. 6 times than outdoor kitchens with the same fuel (44). Another cross-sectional epidemiological study conducted in Southwest China have found that exposure to indoor risk factors, such as air contaminants from coal combustion can reduce FVC and $\mathrm{FEV}_{1}$ (45). Although the prevalence of an enclosed kitchen in Period II (65.0\%) was distinctly higher than that in Period I (50.3\%), the rates of ventilation use when cooking and household coal use in Period II were significantly higher and lower than those in Period I, respectively, i.e., 90.1\% (Period II) vs. 39.5\% (Period I) for ventilation use when cooking and $2.9 \% v s$. $46.8 \%$ for household coal use. Thus, we speculate that an enclosed kitchen in Period I might generate heavier indoor air pollution than the same kitchen in Period II and, consequently, may lead to detrimental effects on children's lung function.

Socioeconomic level was indicated by parental occupation and parental educational level in this study. Compared with Period I, children in Period II were often from homes seldom using coals as household fuels and had advanced ventilation (Table 1). Additionally, an obvious statistically improved education level was observed for parents in Period II, indicating that, after 25 years, socioeconomic conditions have improved. However, although maternal higher education level (which indicates improved socioeconomic condition) was associated with higher lung function in Period II, paternal occupation without fixed income (which is related to lower socioeconomic level) was associated with poorer lung function in Period II. The potential explanation would be that, as an important contributor to household income, the father taking up non-fixed income occupation would mean worse living standards and poorer nutrition status, which could have negative effects on children's lung function (15). Furthermore, in comparison with Period I, maternal occupation without stable income shows an increased negative effect on $\mathrm{FVC}$ and $\mathrm{FEV}_{1}$ in children in Period II (Table S1). This finding indicates that low socioeconomic level is still a risk factor for children's lung function.

Substantial evidence suggests that breastfeeding has a favorable association with lung function in children $(16,46)$. In this study, the proportion of breastfed children in Period II (76.2\%) was significantly higher than that of Period I (72.1\%) ( $\mathrm{P}=0.003)$. In contrast to Period I, the experience of breastfeeding seems to be positively associated with children's lung function in Period II, although not reaching a statistical significance (Table 3), and breastfeeding even seems to have an increasing beneficial effect on children's lung function, particular for PEF (Table S1). Breast milk is rich in immune factors and may facilitate more effective pulmonary immune development and maturation than formula feeding or early solid food consumption (47). Although we did not specify whether the child was exclusively breastfed in both periods, the duration of breastfeeding was surveyed in Period II. With the popularization of breastfeeding knowledge and the establishment of baby-loving hospitals, the rate of exclusive breastfeeding in China is gradually increasing (48). Hence, we speculate that the higher rate of longer breastfeeding duration in Period II (i.e., $64.3 \%$ for breastfeeding $\geq 4$ months) may partly contribute to the difference in effects of breastfeeding on lung function in children. This 
speculation is supported by epidemiology studies that demonstrated that prolonged and exclusive breastfeeding reduces respiratory infection severity and morbidity in infants, limiting virus-induced lung damage $(49,50)$. Furthermore, to study the protective effects of breastfeeding against other risk factors on children's lung function, we evaluated the potential effect of interactions between breastfeeding and household condition on children's lung function in Period I. A higher PEF was found for breastfed children whose family used a ventilation device during cooking, with a $\beta$ value of 655.4 (95\% CI: 57.4, 1,253.4, Table S5), showing a modification effect of ventilation use on lung function in children. This result allows us to add new evidence to literatures by suggesting that the beneficial effect of breastfeeding on children's lung function has increased in recent years.

Lung function depends on a variety of environmental, behavioral, socioeconomic, and parental factors at critical times (6-9). Thus, it is expected that children's lung function will change when there are changes in those influencing factors (51). Some previous studies reported inconsistent and fluctuant changes of $\mathrm{FVC}$ and $\mathrm{FEV}_{1}$ in children in Chinese cities $(52,53)$. It was speculated that the discrepancy in temporal trend of lung function in children might be partly due to the sample size, age ranges, study regions, as well as different study protocols and quality control. Additionally, other causes, such as socioeconomic changes and, ambient air pollution, may also explain some the variations. In this study, we found decreased lung function levels in Wuhan children, based on two cross-sectional studies. Although a higher education level of mother was positively associated with higher $\mathrm{FVC}$ and $\mathrm{FEV}_{1}$, we found a significant negative effect of paternal non-fixed income occupation on FVC and $\mathrm{FEV}_{1}$ in children in Period II. This indicates that socioeconomic factors still had a distinct influence on children's lung function, and lower socioeconomic level could be partly responsible for the decline in lung function in children in Period II. Additionally, although we found decreased ambient air pollution after two decades (Figure S3) (54), air pollution remains an important risk factor for lung function in children (55), which is speculated to be an important contributor to the decrease of lung function in children living in Wuhan. The findings are supported by a cross-sectional study conducted in Wuhan in 2015, showing that males had higher lung function than females; poor ventilation use when cooking and lower household income were both associated with lower lung function; and there was a significant inverse dose-response relationship between $\mathrm{PM}_{10}$ exposure and lung function (56).

There are several limitations to our study. We used household factors such as coal use and ventilation use to indicate indoor air pollution, instead of capturing actual data reflecting indoor air pollutant concentration, which may lead to some uncertainty. Additionally, some factors, such as infant feeding patterns and exposure to moldy environments, were not consistently investigated between the two study periods, which may have induced uncertain biases for the effects of influencing factors and the magnitude of those effects on lung function. Regardless of these limitations, these two cross-sectional studies, with a span of more than two decades between them, provide a valuable opportunity to examine the changes in lung function in children, as well as the changes in influencing factors and the magnitude of their effects.

\section{Conclusions}

Children with the same age range and living in the same areas of Wuhan, China, had significantly lower lung function (FVC and $\mathrm{FEV}_{1}$ ) in 2018 than in 1993-1996. Children's lung function measured in 1993 was adversely affected by an enclosed kitchen. Although there have been substantial socioeconomic developments, better household environments, and improvements of parental factors after more than 20 years, paternal occupation without fixed income in the recent study period was associated with decreased lung function. Additionally, the beneficial effects of urban living condition and breastfeeding were observed in the recent period when heavily-polluting industrial facilities were moved to the suburbs and when breasting feeding was better accepted and promoted. However, there may be other unmeasured factors contributing to the declined lung function in the recent period. Future studies are recommended to investigate the impact of lifestyle, nutrition, early-life exposures, on children's lung function in the modern day.

\section{Acknowledgments}

We are particularly indebted to the children, their parents and the schools for their time and enthusiastic participation. We also appreciate all those who helped us during the implementation of the project.

Funding: This work was supported by the National Key Research and Development Program of China (2016YFC1302501) and the National Science Foundation 
(41977374, 41803016) and Science Foundation of Beijing (7202106).

\section{Footnote}

Provenance and Peer Review: This article was commissioned by the Guest Editors (Junfeng Zhang, Howard Kipen and Haidong Kan) for the series "Children's Respiratory Health and Air Quality" published in Fournal of Thoracic Disease. The article has undergone external peer review.

Reporting Checklist: The authors have completed the STROBE reporting checklist. Available at https://dx.doi. org/10.21037/jtd-21-158

Data Sharing Statement: Available at https://dx.doi. org/10.21037/jtd-21-158

Conflicts of Interest: All authors have completed the ICMJE uniform disclosure form (available at https:// dx.doi.org/10.21037/jtd-21-158). The series "Children's Respiratory Health and Air Quality" was commissioned by the editorial office without any funding or sponsorship. JJZ served as the unpaid Guest Editor of the series. JG and JJZ serves as editorial board members of Fournal of Thoracic Disease. The authors have no other conflicts of interest to declare.

Ethical Statement: The authors are accountable for all aspects of the work in ensuring that questions related to the accuracy or integrity of any part of the work are appropriately investigated and resolved. The study was conducted in accordance with the Declaration of Helsinki (as revised in 2013). This study was approved by the Committee on Ethics of Biomedicine Research, Duke Kunshan University, Jiangsu (NO. FWA00021580), with the need for individual patient consent waived.

Open Access Statement: This is an Open Access article distributed in accordance with the Creative Commons Attribution-NonCommercial-NoDerivs 4.0 International License (CC BY-NC-ND 4.0), which permits the noncommercial replication and distribution of the article with the strict proviso that no changes or edits are made and the original work is properly cited (including links to both the formal publication through the relevant DOI and the license). See: https://creativecommons.org/licenses/by-nc-nd/4.0/.

\section{References}

1. Global Initiative for Asthma. Global Strategy for Asthma Management and Prevention, 2017. Available online: https://ginasthma.org/

2. Fainardi V, Lombardi E. Lung function tests to monitor respiratory disease in preschool children. Acta Biomed 2018;89:148-56.

3. Miller A. Lung function testing: selection of reference values and interpretative strategies. Am Rev Respir Dis 1992;146:1368-9.

4. Li S, Baker PJ, Jalaludin BB, et al. An Australian national panel study of diurnal temperature range and children's respiratory health. Ann Allergy Asthma Immunol 2014;112:348-53.e1-8.

5. Poulain M, Doucet M, Major GC, et al. The effect of obesity on chronic respiratory diseases: pathophysiology and therapeutic strategies. CMAJ 2006;174:1293-9.

6. Hukkinen M, Kaprio J, Broms U, et al. Heritability of lung function: a twin study among never-smoking elderly women. Twin Res Hum Genet 2011;14:401-7.

7. Zhai G, Valdes AM, Cherkas L, et al. The interaction of genes and smoking on forced expiratory volume: a classic twin study. Chest 2007;132:1772-7.

8. Tsui HC, Chen CH, Wu YH, et al. Lifetime exposure to particulate air pollutants is negatively associated with lung function in non-asthmatic children. Environ Pollut 2018;236:953-61.

9. Rice MB, Ljungman PL, Wilker EH, et al. Long-term exposure to traffic emissions and fine particulate matter and lung function decline in the Framingham heart study. Am J Respir Crit Care Med 2015;191:656-64.

10. Kuti BP, Oladimeji OI, Kuti DK, et al. Rural-urban disparity in lung function parameters of Nigerian children: effects of socio-economic, nutritional and housing factors. Pan Afr Med J 2017;28:230.

11. Hegewald MJ, Crapo RO. Socioeconomic status and lung function. Chest 2007;132:1608-14.

12. Moritsugu KP. The 2006 Report of the Surgeon General: the health consequences of involuntary exposure to tobacco smoke. Am J Prev Med 2007;32:542-3.

13. Cheraghi M, Salvi S. Environmental tobacco smoke (ETS) and respiratory health in children. Eur J Pediatr 2009;168:897-905.

14. WHO Guidelines for Indoor Air Quality. Household Fuel Combustion. Geneva, Switzerland: WHO Document Production Services, 2014. 
15. Li W, Liu Q, Chen Y, et al. Effects of indoor environment and lifestyle on respiratory health of children in Chongqing, China. J Thorac Dis 2020;12:6327-41.

16. Zhang C, Guo Y, Xiao X, et al. Association of Breastfeeding and Air Pollution Exposure With Lung Function in Chinese Children. JAMA Netw Open 2019;2:e194186.

17. Gauderman WJ, Urman R, Avol E, et al. Association of improved air quality with lung development in children. $\mathrm{N}$ Engl J Med 2015;372:905-13.

18. Zhang JJ, Hu W, Wei F, et al. Children's respiratory morbidity prevalence in relation to air pollution in four Chinese cities. Environ Health Perspect 2002;110:961-7.

19. Roy A, Hu W, Wei F, et al. Ambient particulate matter and lung function growth in Chinese children. Epidemiology 2012;23:464-72.

20. Wuhan Bureau of Statistics. Statistical Bulletin on National Economic and Social Development [document on the Internet]. 2018. Available online: http://tjj.wuhan. gov.cn/tjfw/tigb/202001/t20200115_841065.shtml

21. Lin J, Lin W, Yin Z, et al. Respiratory health effects of residential individual and cumulative risk factors in children living in two cities of the Pearl River Delta Region, China. J Thorac Dis 2020;12:6342-55.

22. Demissie K, Ernst P, Hanley JA, et al. Socioeconomic status and lung function among primary school children in Canada. Am J Respir Crit Care Med 1996;153:719-23.

23. Talaminos Barroso A, Márquez Martín E, Roa Romero LM, et al. Factors Affecting Lung Function: A Review of the Literature. Arch Bronconeumol (Engl Ed) 2018;54:327-32.

24. Stocks J, Lum S. 11 - Pulmonary function tests in infants and preschool children. In: Wilmott RW, Boat TF, Bush A, et al. editors. Kendig \& Chernick's Disorders of the Respiratory Tract in Children. 8th edition. Elsevier, 2012:169-210.

25. Cao S, Wen D, Li S, et al. Changes in children's asthma prevalence over two decades in Lanzhou: effects of socioeconomic, parental and household factors. J Thorac Dis 2020;12:6365-78.

26. Mottram C. Ruppel's manual of pulmonary function testing. 10th edition. Maryland Heights, Missouri: Mosby, 2012.

27. Sharma G, Goodwin J. Effect of aging on respiratory system physiology and immunology. Clin Interv Aging 2006; 1:253-60.

28. Lee B, Park S, Han D. Analysis of the influential factors of maximal-effort expiratory capacity of elderly women. J Phys Ther Sci 2016;28:2924-8.
29. Vaz Fragoso CA, McAvay G, Van Ness PH, et al. AgingRelated Considerations When Evaluating the Forced Expiratory Volume in 1 Second (FEV1) Over Time. J Gerontol A Biol Sci Med Sci 2016;71:929-34.

30. Lalley PM. The aging respiratory system--pulmonary structure, function and neural control. Respir Physiol Neurobiol 2013;187:199-210.

31. Quanjer PH, Capderou A, Mazicioglu MM, et al. Allage relationship between arm span and height in different ethnic groups. Eur Respir J 2014;44:905-12.

32. Al Ghobain M. The effect of obesity on spirometry tests among healthy non-smoking adults. BMC Pulm Med 2012;12:10.

33. Das D, Mondal H, Patnaik M. Study of dynamic lung function parameters in normal, overweight, and thin school boys. J Sci Soc 2017;44:36-9.

34. McCallister JW, Adkins EJ, O'Brien JM Jr. Obesity and acute lung injury. Clin Chest Med 2009;30:495-508, viii.

35. Beuther DA. Recent insight into obesity and asthma. Curr Opin Pulm Med 2010;16:64-70.

36. Kastner-Cole D, Palmer CN, Ogston SA, et al. Overweight and obesity in deltaF508 homozygous cystic fibrosis. J Pediatr 2005;147:402-4.

37. Stephenson AL, Mannik LA, Walsh S, et al. Longitudinal trends in nutritional status and the relation between lung function and BMI in cystic fibrosis: a population-based cohort study. Am J Clin Nutr 2013;97:872-7.

38. Morgan BW, Siddharthan T, Grigsby MR, et al. Asthma and Allergic Disorders in Uganda: A Population-Based Study Across Urban and Rural Settings. J Allergy Clin Immunol Pract 2018;6:1580-1587.e2.

39. Al-Qerem WA, Ling J. Pulmonary function tests in Egyptian schoolchildren in rural and urban areas. East Mediterr Health J 2018;24:325-32.

40. Dashdendev B, Fukushima LK, Woo MS, et al. Carbon monoxide pollution and lung function in urban compared with rural Mongolian children. Respirology 2011;16:653-8.

41. Balakrishnan L, Rennie D, Dosman J, et al. Lung function in relation to farm dwelling and farming activities in rural dwelling children. Respirology 2017;22:1320-8.

42. Fuchs O, Genuneit J, Latzin P, et al. Farming environments and childhood atopy, wheeze, lung function, and exhaled nitric oxide. J Allergy Clin Immunol 2012;130:382-8.e6.

43. Xu G, Jiao LM, Zhao SL, et al. Spatial and temporal variability of air quality in Wuhan city from 1990 to 2004. Environmental Engineering 2016;34:80-5.

44. Deepthi Y, Shiva Nagendra SM, Gummadi SN. 
Characteristics of indoor air pollution and estimation of respiratory dosage under varied fuel-type and kitchentype in the rural areas of Telangana state in India. Sci Total Environ 2019;650:616-25.

45. Li S, Xu J, Jiang Z, et al. Correlation between indoor air pollution and adult respiratory health in Zunyi City in Southwest China: situation in two different seasons. BMC Public Health 2019;19:723.

46. Waidyatillake NT, Allen KJ, Lodge CJ, et al. The impact of breastfeeding on lung development and function: a systematic review. Expert Rev Clin Immunol 2013;9:1253-65.

47. Ballard O, Morrow AL. Human milk composition: nutrients and bioactive factors. Pediatr Clin North Am 2013;60:49-74.

48. Wuhan Bureau of Statistics. Statistical monitoring report on child development planning [document on the Internet]. 2019. Available online: http://tjj.wuhan.gov.cn/ tjfw/tjfx/202007/t20200713_1401401.shtml

49. Verduci E, Martelli A, Miniello VL, et al. Nutrition in the first 1000 days and respiratory health: A descriptive review of the last five years' literature. Allergol Immunopathol (Madr) 2017;45:405-13.

50. Yamakawa M, Yorifuji T, Kato T, et al. Long-Term Effects of Breastfeeding on Children's Hospitalization for Respiratory

Cite this article as: Cao S, Wen D, Li S, Guo Q, Duan X, Gong J, Xu X, Meng X, Qin N, Wang B, Zhang JJ. Changes in children's lung function over two decades in relation to socioeconomic, parental and household factors in Wuhan, China. J Thorac Dis 2021;13(7):4601-4613. doi: 10.21037/jtd-21-158
Tract Infections and Diarrhea in Early Childhood in Japan. Matern Child Health J 2015;19:1956-65.

51. Du J. Economic reforms and health insurance in China. Soc Sci Med 2009;69:387-95.

52. Neukirch F, Chansin R, Liard R, et al. Spirometry and maximal expiratory flow-volume curve reference standards for Polynesian, European, and Chinese teenagers. Chest 1988;94:792-8.

53. Gao C, Zhang X, Wang D, et al. Reference values for lung function screening in 10- to 81-year-old, healthy, never-smoking residents of Southeast China. Medicine (Baltimore) 2018;97:e11904.

54. Yin Z, Huang X, He L, et al. Trends in ambient air pollution levels and PM2.5 chemical compositions in four Chinese cities from 1995 to 2017. J Thorac Dis 2020;12:6396-410.

55. Li S, Cao S, Duan X, et al. Long-term exposure to PM2.5 and Children's lung function: a dose-based association analysis. J Thorac Dis 2020;12:6379-95.

56. Song YC. Association between exposure to environmental air particulate matter and declined lung function in Wuhan community population. Wuhan: Huazhong University of Science \& Technology, 2015. 
A

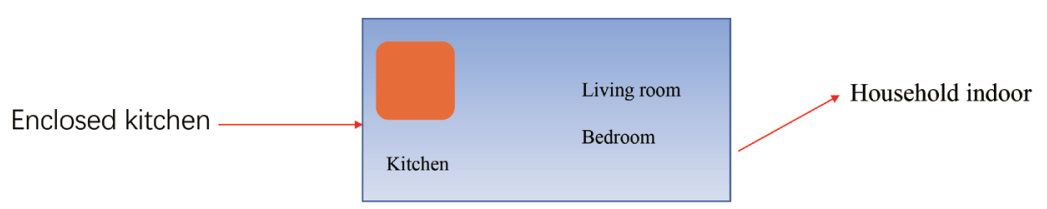

B

C

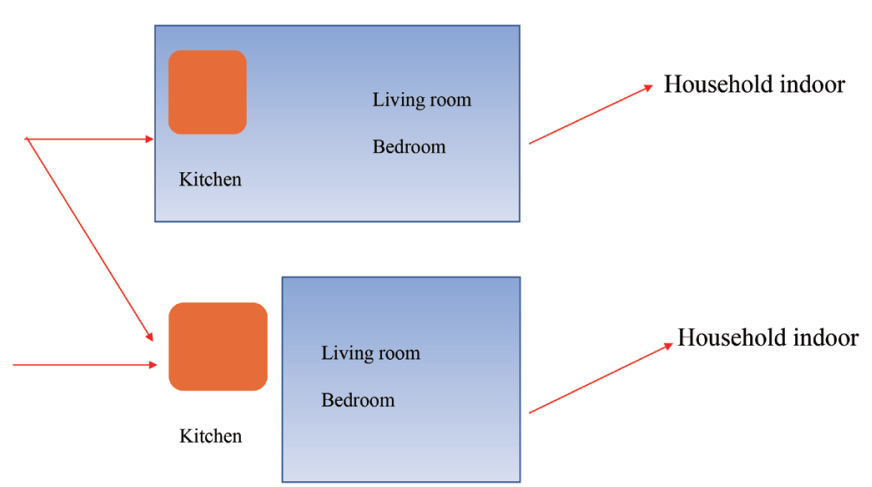

Figure S1 Description of various kitchen types. (A) Enclosed kitchen, represents inside or opening kitchen, which is defined as a kitchen that was not isolated to the living room or bedroom with a door or other device; (B) separated kitchen, represents the kitchen which is isolated to the living room or bedroom with a door or other device, and also represents the kitchen which is separate outside the house (i.e., the kitchen of kind of $\mathrm{C}$ ); (C) outdoor kitchen, represents to the kitchen which is separate outside the house. 


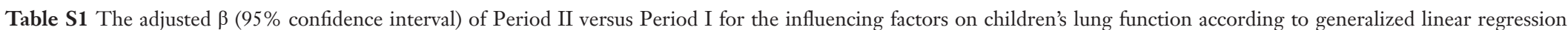
models, correlating all the confounders studied

\begin{tabular}{|c|c|c|c|c|}
\hline Variables & $\mathrm{FVC}, \mathrm{mL}$ & $\mathrm{FEV}_{1}, \mathrm{~mL}$ & $\mathrm{PEF}, \mathrm{mL} / \mathrm{s}$ & FEF25-75, mL/s \\
\hline$M 0^{1}+$ study period $\times$ district (ref: urban) & $-54.6(-149.2,40.0)$ & $-38.4(-115.9,39.0)$ & $1,394.8(946.0,1,843.5)^{\star \star}$ & $-45.5(-198.3,107.2)$ \\
\hline M0 + study period $\times$ household coal use (ref: no) & $-92.8(-307.9,122.4)$ & $-20.6(-196.9,155.6)$ & $268.5(-777.3,1,314.3)$ & $402.9(56.8,749.1)^{\star \star}$ \\
\hline M0 + study period $\times$ ventilation use when cooking (ref: no) & $-12.3(-547.7,523.2)$ & $-37.8(-476.2,400.7)$ & $169.4(-2,432.3,2,771.0)$ & $-139.9(-1,003.9,723.9)$ \\
\hline MO + study period $\times$ enclosed kitchen (ref: no) & $33.4(-39.3,106.2)$ & $47.3(-41.4,136.1)$ & $-152.2(-583.7,279.4)$ & $51.6(-91.6,194.9)$ \\
\hline MO + study period $\times$ father being white collar (ref: blue collar) & $-8.7(-105.5,88.2)$ & $-11.8(-91.1,67.6)$ & $174.4(-295.8,644.6)$ & $140.6(-15.0,296.3)$ \\
\hline M0 + study period $\times$ father without stable income (ref: blue collar) & $-122.1(-277.8,33.6)$ & $-90.6(-218.1,36.9)$ & $-563.9(-1,319.7,191.9)$ & $-205.6(-455.8,44.6)$ \\
\hline M0 + study period $\times$ mother being white collar (ref: blue collar) & $82.6(-18.3,183.5)$ & $45.5(-37.3,128.2)$ & $-98.3(-591.1,394.4)$ & $54.5(-109.5,218.5)$ \\
\hline $\mathrm{MO}+$ study period $\times$ mother without stable income (ref: blue collar) & $-154.1(-304.2,-3.87)^{\star}$ & $-135.7(-258.9,-12.6)^{*}$ & $-717.4(-1,450.4,15.7)$ & $39.3(-204.7,283.3)$ \\
\hline M0 + study period $\times$ paternal education (ref: < college) & $46.7(-74.7,168.1)$ & $50.9(-48.5,150.3)$ & $-121.6(-711.9,468.7)$ & $174.9(-20.7,370.6)$ \\
\hline M0 + study period × maternal education (ref: < college) & $148.5(-10.0,307.1)$ & $83.2(-46.8,213.1)$ & $-207.0(-978.9,564.9)$ & $135.0(-121.2,391.2)$ \\
\hline M0 + study period $\times$ breast feeding (ref: no) & $58.9(-45.2,162.9)$ & $71.1(-14.1,156.2)$ & $540.1(35.5,1,044.7)^{\star \star}$ & $149.8(-17.9,317.6)$ \\
\hline
\end{tabular}

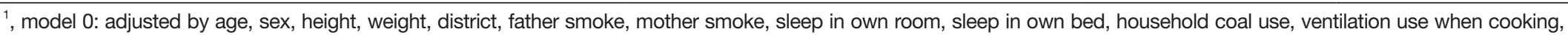

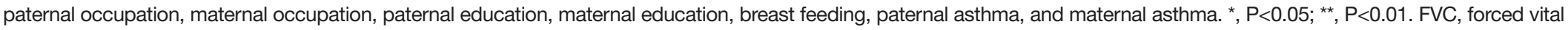
capacity; FEV $_{1}$, forced expiratory volume in the first second; PEF, peak expiratory flow; FEF25-75, forced expiratory flow at $25 \%$ and $75 \%$ of the pulmonary volume.

Table S2 Lung function in children with different BMI status in Period II (2018)

\begin{tabular}{|c|c|c|c|c|c|}
\hline Variables & Normal $(\mathrm{N}=283)$, mean (SD) & Overweight $(\mathrm{N}=53)$, mean $(\mathrm{SD})$ & Obesity (N=47), mean (SD) & Overall $(\mathrm{N}=383)$, mean $(\mathrm{SD})$ & $P$ value \\
\hline FVC, mL & $1,740(422)$ & $1,990(415)$ & 2,190 (918) & $1,830(531)$ & 0.001 \\
\hline $\mathrm{FEV}_{1}, \mathrm{~mL}$ & $1,660(374)$ & $1,890(387)$ & $2,010(657)$ & $1,740(439)$ & 0.001 \\
\hline $\mathrm{PEF}, \mathrm{mL} / \mathrm{s}$ & $3,250(960)$ & $3,760(1,070)$ & $3,890(633)$ & $2,410(669)$ & 0.001 \\
\hline FEF25-75, mL/s & $2,350(661)$ & $2,580(685)$ & $2,630(633)$ & $2,410(669)$ & 0.0014 \\
\hline
\end{tabular}

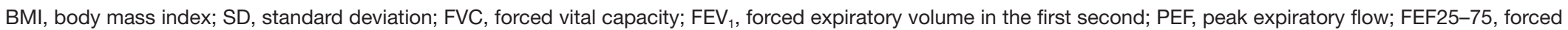
expiratory flow at $25 \%$ and $75 \%$ of the pulmonary volume.

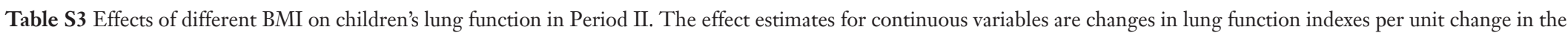
variable and those for categorical variables are differences from the reference group

\begin{tabular}{|c|c|c|c|c|c|c|c|c|}
\hline \multirow{2}{*}{ BMI types } & \multicolumn{2}{|c|}{$\mathrm{FVC}, \mathrm{mL}$} & \multicolumn{2}{|l|}{$\mathrm{FEV}_{1}, \mathrm{~mL}$} & \multicolumn{2}{|l|}{ PEF, mL/s } & \multicolumn{2}{|c|}{ FEF25-75, mL/s } \\
\hline & $\beta(95 \% \mathrm{Cl})$ & $\mathrm{P}$ & $\beta(95 \% \mathrm{Cl})$ & $P$ & $\beta(95 \% \mathrm{Cl})$ & $P$ & $\beta(95 \% \mathrm{Cl})$ & $P$ \\
\hline Overweight (ref: normal) & $201.1(67.2,334.9)$ & 0.003 & $200.9(83.1,318.8)$ & 0.001 & $304.5(-19.7,628.8)$ & 0.066 & $111.9(-104.4,328.3)$ & 0.311 \\
\hline Obesity (ref: normal) & $286.1(132.9,439.3)$ & 0.000 & $290.3(155.4,425.2)$ & 0.000 & $819.5(448.5,1,190.5)$ & 0.000 & $548.1(300.5,795.7)$ & 0.000 \\
\hline
\end{tabular}

$\mathrm{Cl}$, confidence interval. 
Table S4 The characteristics of determinant household conditions involved with fuel used in cooking/heating, ventilation use, etc., between urban and suburban areas after 25 years

\begin{tabular}{lcc}
\hline Variables & Urban $(\mathrm{n}=491)$ & Rural (n=383) \\
\hline Household coal use, $\mathrm{n}(\%)$ & & $127(91.4)$ \\
No & $236(96.7)$ & $7(5.0)$ \\
Yes & $4(1.6)$ & $5(3.6)$ \\
Missing & $4(1.6)$ & $2(1.4)$ \\
Ventilation use when cooking, $\mathrm{n}(\%)$ & $2(0.8)$ & $122(87.8)$ \\
No & $223(91.4)$ & $15(10.8)$ \\
Yes & $19(7.8)$ & 0.5456 \\
Missing & & $54(38.8)$ \\
Close/outside kitchen, $\mathrm{n}(\%)$ & $65(26.6)$ & $78(56.1)$ \\
No & $171(70.1)$ & $7(5.0)$ \\
Yes & $8(3.3)$ & 0.0087 \\
Missing & & 7 \\
\hline
\end{tabular}




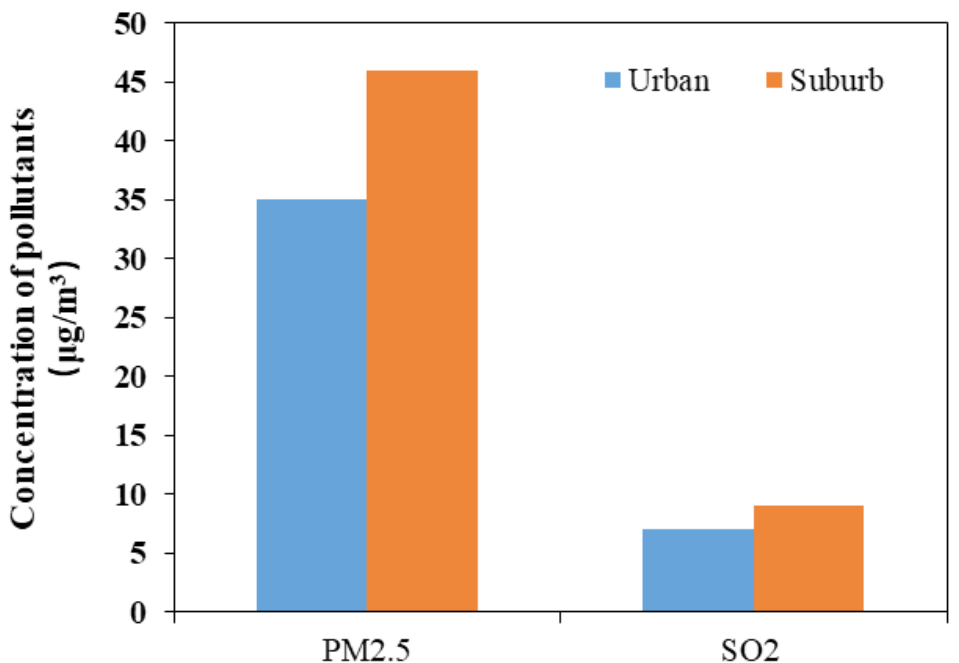

Figure S2 Concentrations of major atmospheric pollutants in urban and suburban areas in Wuhan in 2018 (data was obtained from the National monitoring station data released by the Ministry of Ecology and Environment).

Table S5 Adjusted association ( $\beta, 95 \%$ confidence interval) of household factors $\times$ breastfeeding in Period I for children's lung function according to multi linear regression models correlating all the confounders studied

\begin{tabular}{lcccc}
\hline Variables & FVC, $\mathrm{mL}$ & FEV, $\mathrm{mL}$ & PEF, mL/s & FEF25-75, mL/s \\
\hline Urban $\times$ breastfeeding & $-0.2(-90.7,90.4)$ & $-36.5(-112.7,39.7)$ & $498.9(-145.4,1143.2)$ & $-114.8(-269.2,39.6)$ \\
Enclosed kitchen $\times$ breastfeeding & $2.6(-81.2,86.5)$ & $30.1(-40.6,100.6)$ & $-238.3(-836.1,359.5)$ & $-0.2(-143.5,143.1)$ \\
Household coal use $\times$ breastfeeding & $44.6(-37.8,126.9)$ & $40.4(-28.9,109.8)$ & $-619.9(-1205.6,-34.1)$ & $74.9(-65.9,215.7)$ \\
Ventilation when cooking $\times$ breastfeeding & $37.4(-46.8,121.5)$ & $15.0(-55.9,85.9)$ & $655.4(57.4,1253.4)^{\star}$ & $-23.8(-167.7,120.2)$ \\
\hline
\end{tabular}

Adjusted by age, sex, weight, height, district, father smoke, mother smoke, sleep in own room, sleep in own bed, household coal use, ventilation use when cooking, paternal occupation, maternal occupation, paternal education level, maternal education level, breast feeding. *, $\mathrm{P}<0.05$. FVC, forced vital capacity; FEV ${ }_{1}$, forced expiratory volume in the first second; PEF, peak expiratory flow; FEF25-75, forced expiratory flow at $25 \%$ and $75 \%$ of the pulmonary volume. 


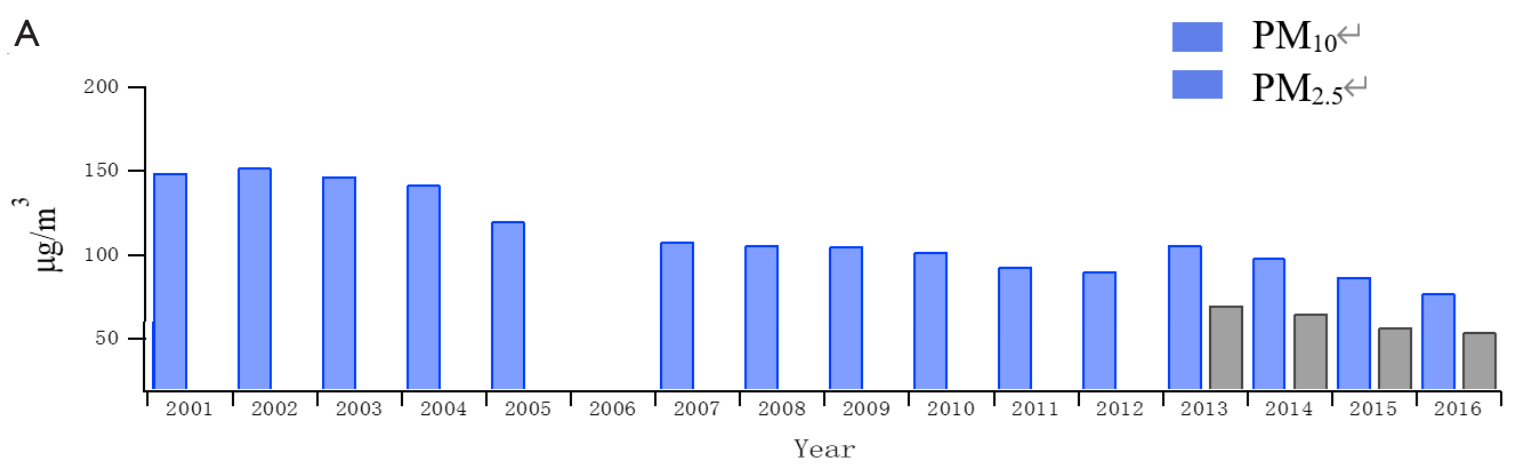

B

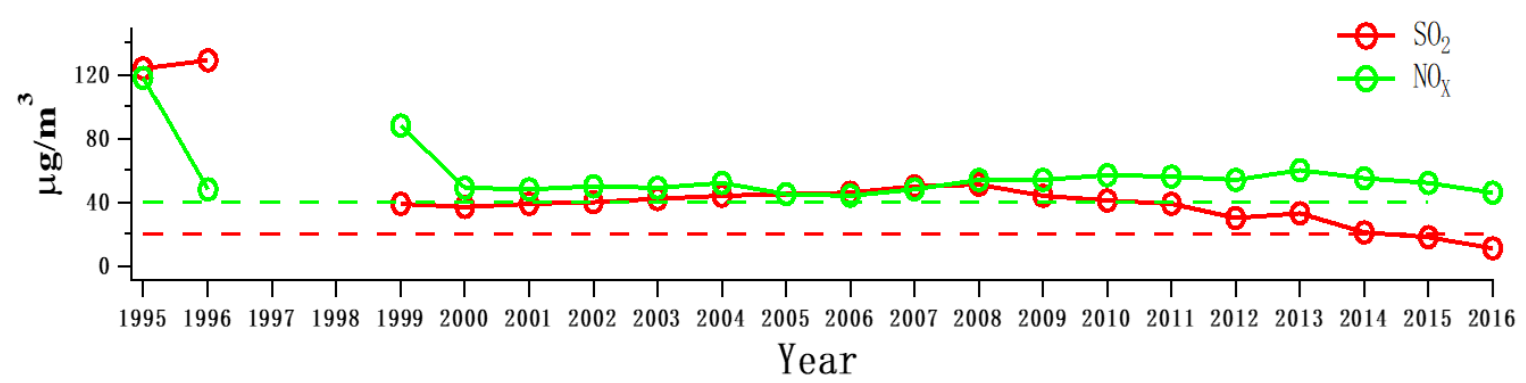

Figure S3 Annual means of fine particulate matter $\left(\mathrm{PM}_{2.5}\right)$ and particulate matter $\left(\mathrm{PM}_{10}\right)(\mathrm{A})$, and nitrogen dioxide $\left(\mathrm{NO}_{2}\right)$ and sulfur dioxide $\left(\mathrm{SO}_{2}\right)$ concentrations (B) for the period 1995-1996 and 2013-2016 (data was obtained from the National monitoring station data released by the Ministry of Ecology and Environment). 